\title{
Recovering tungsten from mine tailings: Characterization, aqueous geochemistry and environmental risk
}

\author{
H.E. JAMIESON ${ }^{1 *}$, B. KAZAMEL ${ }^{1}$, M. LEYBOURNE ${ }^{1}$, A. \\ SURRETTE $^{1}$, H. FALCK ${ }^{2}$ \\ ${ }^{1}$ Department of Geological Sciences \& Geological \\ Engineering, Queen's University, Kingston, Ontario, \\ Canada K7L 3N6. (*correspondence: \\ jamieson@queensu.ca) \\ ${ }^{2}$ Government of the Northwest Territories, Yellowknife, NT \\ X1A 2L9 (hendrik.falck@gov.nt.ca)
}

Reprocessing mine waste to extract additional value is a potentially sustainable alternative to exploration and development of new mines, particularly if it involes a reduction in environmental risk. At Cantung mine in northern Canada, tailings contain ore grade values of tungsten and minor additional value of copper and gold. Automated mineralogy was used to determine modal mineralogy, grain size and degree of liberation. Tungsten is present exclusively as scheelite accompanied by calc-silicate minerals and up to $40 \%$ pyrrhotite. The tailings are currently in impoundments with little sulfide oxidation and near-neutral porewater $\mathrm{pH}$. Older tails were deposited on the Flat river floodplain and exhibit extensive replacement of sulfide by goethite, gypsum, sulfur and jarosite, and pore water $\mathrm{pH}$ as low as 2 . Tungsten, known to be toxic under some conditions, has concentrations in surface and pore waters ranging from 5.3 to $26.3 \mu \mathrm{g} / \mathrm{L}$ in samples with pHs between 7 and 8 , whereas samples below pH 7 are below the detection limit of $300 \mathrm{ng} / \mathrm{L}$. Regulatory authorities have reccomended that to increase geotechnical stability, the steep-sided tailings impoundments be replaced by dry-stack storage which involves partially dewatered tailings vulnerable to oxidation.

Our long-term objective is to assist in transforming the Cantung mine from an inactive and environmentally problematic site in a vulnerable Northern setting to one where additional value can be efficiently extracted from tailings with a comprehensive remediation design that reduces environmental risk. Our research program includes characterization, reprocessing design, investigation of tungsten mobility and testing long-term stability under dry stack conditions. 